\title{
Reading time data for evaluating broad-coverage models of English sentence processing
}

\author{
Stefan L. Frank • Irene Fernandez Monsalve • \\ Robin L. Thompson • Gabriella Vigliocco
}

Published online: 13 February 2013

(C) Psychonomic Society, Inc. 2013

\begin{abstract}
We make available word-by-word self-paced reading times and eye-tracking data over a sample of English sentences from narrative sources. These data are intended to form a gold standard for the evaluation of computational psycholinguistic models of sentence comprehension in English. We describe stimuli selection and data collection and present descriptive statistics, as well as comparisons between the two sets of reading times.
\end{abstract}

Keywords Word-reading time $\cdot$ Self-paced reading $\cdot$ Eye tracking $\cdot$ Sentence comprehension $\cdot$ Model evaluation

\section{Introduction}

In recent years, models from the field of computational linguistics have increasingly been used for explaining psycholinguistic data, and conversely, psycholinguistic data have increasingly been used to evaluate computational models. In contrast to typical psychological models, the algorithms developed by computational linguists are rarely intended to explain specific phenomena. Rather, they have broad coverage, being able to handle sentences in natural language. As such, it has become common practice to evaluate these models by comparing their word-level predictions with human word-reading times collected over general texts. The data set most often used in this context is the Dundee corpus (Kennedy \& Pynte, 2005), comprising eye-tracking data of 10 subjects reading newspaper editorials in

Electronic supplementary material The online version of this article (doi:10.3758/s13428-012-0313-y) contains supplementary material, which is available to authorized users.

S. L. Frank $(\bowtie) \cdot$ I. Fernandez Monsalve • R. L. Thompson •

G. Vigliocco

Department of Cognitive, Perceptual and Brain Sciences,

University College London, London, UK

e-mail: s.frank@ucl.ac.uk

\section{R. L. Thompson}

Deafness, Cognition and Language Research Centre, London, UK
English. These data have been used for model evaluation by, among others, Demberg and Keller (2008); Fossum and Levy (2012); Frank and Bod (2011), and Mitchell, Lapata, Demberg, and Keller (2010). Alternatively, model predictions have also been compared with self-paced reading data over English narrative texts (Roark, Bachrach, Cardenas, \& Pallier, 2009; Wu, Bachrach, Cardenas, \& Schuler, 2010).

Two potential problems arise when using newspaper or narrative texts for model evaluation. First, the sentenceprocessing models invariably treat sentences as independent entities, whereas the interpretation of a sentence in text depends on the previous sentences. Second, and perhaps more important, understanding newspaper or narrative texts requires vast amounts of extra-linguistic knowledge to which the models have no access. For these reasons, a more appropriate data set for model evaluation would consist of independent sentences that can be understood out of context. One such data set is the Potsdam Corpus of 144 German sentences with eye-tracking data of 222 subjects (Kliegl, Nuthmann, \& Engbert, 2006), used for model evaluation by Boston, Hale, Patil, Kliegl, and Vasishth (2008) and Boston, Hale, Vasishth, and Kliegl (2011). However, the Potsdam Corpus sentences are unlikely to form a representative sample of the language, because they were manually constructed as experimental stimuli.

Here, we present a collection of reading time data that is intended to serve as a gold standard for evaluating computational psycholinguistic models of English sentence comprehension. The word-reading times were obtained using two different paradigms: self-paced reading and eye tracking. These data were collected over independent English sentences that (unlike those of the Potsdam Corpus) were not constructed for experimental purposes. Instead, they were selected from different narrative sources and, as such, can be considered a "sample" of written narrative English, comprising a wide range of structures.

The following sections discuss the selection of stimulus material, provide details of how the reading times were collected, and present descriptive statistics of the data, as well as results of comparisons between the two paradigms. All materials and 
data are available as online supplementary material. Appendix 1 lists the available data files and describes their content.

\section{Method}

Stimuli selection

On the Web site www.free-online-novels.com, aspiring authors can upload their (otherwise unpublished) work. We selected three novels that were categorized under different genres, all of which used British English spelling. These were Aercu by Elisabeth Kershaw, The Unlikely Hero by Jocelyn Shanks, and Hamsters! (or: What I Did On My Holidays by Emily Murray) by Daniel Derrett.

Next, a list of 7,754 words was constructed by merging the list of high-frequency content words used in Andrews, Vigliocco, and Vinson (2009) with the 200 most frequent English words (mostly function words). The list included two punctuation marks: the comma and the period. From the three novels, all sentences were selected that contained only words from the word list, were at least five words long, and included at least two content words. ${ }^{1}$ Of the resulting sentences, we hand-picked the 361 that could be interpreted out of context with only minimal involvement of extra-linguistic knowledge. The average sentence length was 13.7 words $(S D, 6.36$; median, 12; maximum, 38). For 166 of the sentences, yes/no comprehension questions were constructed.

Obvious typos and grammatical errors were fixed. To prevent subjects from connecting the sentence stimuli into a story, proper names were replaced by same-gender names (from the high-frequency word list) such that no name appeared more than twice across the stimuli. A selection of the resulting sentences is presented in Appendix 2.

Fernandez Monsalve, Frank, and Vigliocco (2012) annotated the sentences with part-of-speech tags - that is, labels indicating the words' syntactical categories. Labels were first generated automatically by a part-of-speech tagging algorithm (Tsuruoka $\&$ Tsuji, 2005), after which they were manually corrected to comply with the Penn Treebank tagging guidelines (Santorini, 1991). This annotation is also available as online supplementary material but is not relevant to the collection of reading time data.

\section{Self-paced reading}

\section{Subjects}

One hundred seventeen first-year students (92 females, 70 native English speakers, mean age $=18.9$ years) of psychology

\footnotetext{
${ }^{1}$ As an additional constraint, at least one of the words had to be one for which Andrews et al.(2009) provided human-generated semantic features. This was to allow for investigating possible within-sentence semantic priming effects.
}

at University College London participated in the self-paced reading study as part of their undergraduate degree.

\section{Procedure}

The study was preceded by an unrelated lexical decision experiment that took approximately $10 \mathrm{~min}$, after which followed six self-paced reading practice trials. Sentence stimuli were repeatedly selected at random from the 361 experimental sentences until $40 \mathrm{~min}$ had elapsed (including time spent on the lexical decision and practice trials). Each sentence was preceded by a fixation cross, presented centrally on a computer monitor. As soon as the subject pressed the space bar, the fixation cross was replaced by the sentence's first word in 40-point Courier New font. At each subsequent keypress, the current word was replaced by the next, always at the same central location on the display. The time between word presentation and keypress was recorded as the reading time on that word. Punctuation marks were presented together with the directly preceding word. After completion of a sentence, the corresponding comprehension question (if any) appeared, and subjects responded yes or no by pressing the J or F key, respectively.

\section{Eye tracking}

\section{Materials and subjects}

Of the original 361 sentence stimuli, the 205 that fit on a single line of the display were used in the eye-tracking study. These selected sentences are listed in Appendix 2.

Forty-eight subjects, recruited from the University College London subject pool, took part, for which they were paid $£ 7$. Four subjects were excluded due to technical issues, and 1 because he had already taken part in the self-paced reading study, leaving 43 subjects (27 females, 37 native English speakers, mean age $=25.8$ years) with analyzed data.

\section{Procedure}

Subjects were seated $50 \mathrm{~cm}$ from the monitor with their chin on a chinrest. Both eyes were tracked using a head-mounted eyetracker (SR Research, EyeLink II). Individual sentences were presented in 18-point Courier font, left-aligned on the display. Punctuation marks were attached to the directly preceding word. Each sentence was preceded by a leftaligned fixation cross that was presented for $800 \mathrm{~ms}$. Gaze direction was sampled at a rate of $500 \mathrm{~Hz}$.

After initial calibration (nine fixation points) and 5 practice trials, subjects were invited to ask clarification questions, and the experiment began. Another calibration check was performed after the practice items and then again after every 35 trials, at which time subjects took a self-paced break (the final set had only 30 trials, for a total of 205 trials over six sets). 

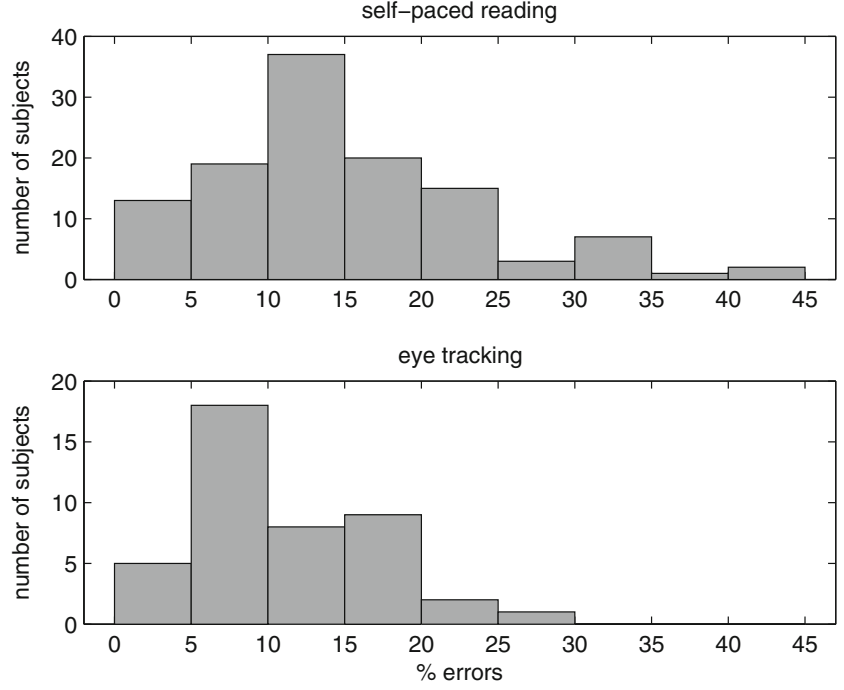

Fig. 1 Distribution of subjects over error rates

Additionally, drift correction on a single centrally located fixation point was performed before the start of each trial. Responses were recorded using a mouse (center button to continue after finishing a sentence; right and left buttons to respond yes or no, respectively, to comprehension questions). The entire experiment, including instructions and calibration, took approximately $60 \mathrm{~min}$ to complete. The order of sentence presentation was randomized throughout.

\section{Word-reading times}

A word was considered as not fixated if the first fixation on that word occurred after any fixation on a word further to the

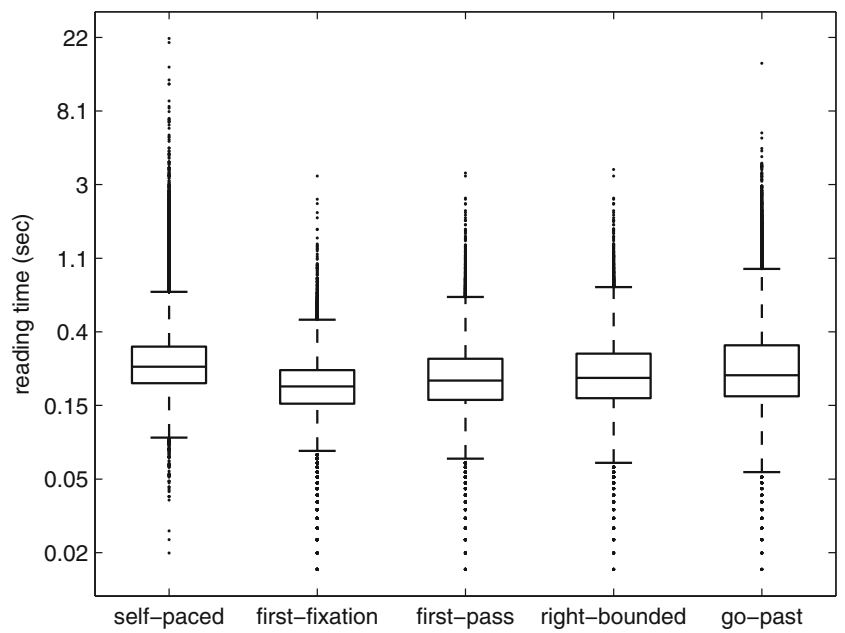

Fig. 2 Boxplots of log-transformed reading time data. Boxes denote the lower quartile, median, and upper quartile; whiskers extend to 1.5 times the interquartile range. Note that labels on the vertical axis are nontransformed reading times right. Four measures of reading time were extracted from the eye-tracking data:

- First-fixation time: duration of only the first fixation on the current word.

- First-pass time (also known as gaze duration): summed duration of all fixations on the current word before the first fixation on any other word.

- Right-bounded time: summed duration of all fixations on the current word before the first fixation on a word further to the right.

- Go-past time (also known as regression-path time): summed duration of all fixations from the first fixation on the current word up to (but not including) the first fixation on a word further to the right. Note that this often includes fixations on words to the left of the current word.

\section{Results and discussion}

\section{Error rates}

The percentage of response errors to comprehension questions was significantly larger in the self-paced reading study, as compared with eye tracking ( $15.8 \%$ and $11.5 \%$, respectively), $z=6.91, p<.0001$. As is apparent from the histograms in Fig. 1, this difference was mainly caused by a number of self-paced reading subjects who scored very badly, which we ascribe to a lack of motivation due to their compulsory participation. From hereon, we discard data by subjects who had an error rate above 25\%, which leaves 104 self-paced reading and 42 eye-tracking subjects and decreases the respective average error rates to $13.0 \%$ and $11.2 \%$. Although the difference in error rate between the two paradigms has now been reduced, it remains statistically significant, $z=2.99, p<.003$.

\section{Reading times}

Predictions by different broad-coverage statistical language models were evaluated on the native speakers' self-paced reading (Fernandez Monsalve et al., 2012; Frank, in press) and eye tracking (Frank \& Thompson, 2012) data. ${ }^{2}$ All three studies showed that a word takes longer to read if the models predict that it will lead to increased cognitive-processing load. This establishes the validity of the models, but also of the data.

Here, we focus on descriptive statistics of the reading time data and on comparing the two experimental paradigms. Words attached to punctuation (including all sentence-final words) and nonfixated words were not included in the analysis

\footnotetext{
${ }^{2}$ Frank and Thompson (2012) included only the 17 monolingual subjects who were tested at the time.
} 


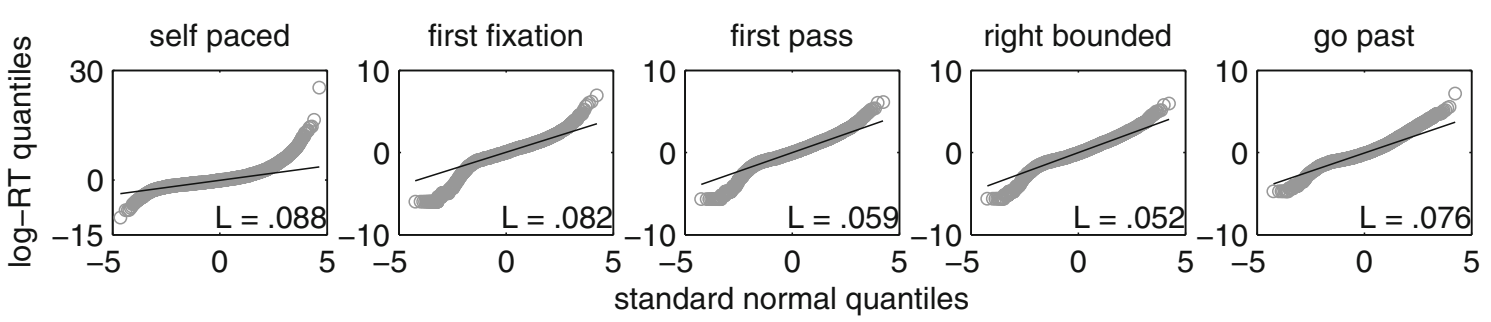

Fig. 3 Quantile-quantile plots of standardized log-transformed reading times against a standard normal distribution and $L$-statistics of Lilliefors tests of normality (larger $L$ corresponds to stronger deviance from a normal distribution)

(the percentage of nonfixated words was $34.0 \%$ overall but varied widely among subjects, from $5.5 \%$ to $60.4 \%$ ). Also, three sentences that contained a typo in the self-paced reading study were removed, leaving 274,893 and 44,371 data points from self-paced reading and eye tracking, respectively.

\section{Reading time distributions}

The distribution of each set of reading time data (aggregated over all subjects and after log-transformation) can be seen in the boxplots of Fig. 2. It is clear that the distributions have "fat tails"; that is, they are not normally distributed but have excess kurtosis. This is also evident from the quantilequantile plots of Fig. 3, where log-transformed reading times are standardized per subject. None of the distributions are normal, as is confirmed by Lilliefors tests for normality (Lilliefors, 1967), the test statistics of which are also plotted in the figure (all $p \mathrm{~s}<.001$ ).

\section{Comparison between paradigms}

Table 1 shows the Spearman rank correlations between reading times (averaged over subjects) from the self-paced reading and eye-tracking studies. In order to detect possible spillover and parafoveal preview effects, correlations are also presented for "misaligned" reading times; that is, reading times from eye tracking are correlated to the self-paced reading time of the previous or next word.

Table 1 Spearman's rank correlation between eye-tracking reading times on words at position $t$ and self-paced reading times of words at $t-1, t$, and $t+1$

\begin{tabular}{llllll}
\hline & \multicolumn{4}{l}{ Eye tracking RT at word $t$} \\
\cline { 2 - 6 } & & $\begin{array}{l}\text { First } \\
\text { fix }\end{array}$ & $\begin{array}{l}\text { First } \\
\text { pass }\end{array}$ & $\begin{array}{l}\text { Right } \\
\text { bound }\end{array}$ & $\begin{array}{l}\text { Go } \\
\text { past }\end{array}$ \\
\hline Self-paced RT & $t-1$ & .022 & .050 & $.073^{*}$ & $.079^{*}$ \\
& $t$ & $.161^{* *}$ & $.206^{* *}$ & $.224^{* *}$ & $.185^{* *}$ \\
& $t+1$ & $.187^{* *}$ & $.232^{* *}$ & $.253^{* *}$ & $.219^{* *}$ \\
\hline
\end{tabular}

${ }^{*} p<.05$

$* * p<.0001$
The correlations between eye tracking and self-paced reading times are much larger when looking at self-paced times on the current or next word (second and third rows of Table 1) than on the previous word (first row). This means that the keypresses in the self-paced reading study lag behind eye fixations, whereas the reverse is less evident. Apparently, there is a stronger spillover effect in self-paced reading than in eye tracking, as is consistently found when comparing the two paradigms (e.g., Just, Carpenter, \& Woolley, 1982; Witzel, Witzel, \& Forster, 2012). In addition, the positive correlation between fixation durations at $t$ and self-paced reading times at $t+1$ could be due to parafoveal preview in the eye-tracking study. In that case, processing difficulty caused by the upcoming word is already apparent while the eye is still fixated on the current word. However, whether such parafoveal-on-foveal effects indeed occur is controversial (for a review, see Schotter, Angele, \& Rayner, 2012).

\section{Conclusion}

The data we have presented can further the field of computational psycholinguistics by allowing for a comparison among different model's psychological adequacy on one and the same set of data. As was argued in the Introduction, these data may be more appropriate for such evaluation than the reading times over narrative or expository texts that have been used so far. Also, our sample of sentences is more representative of the language than are sentences that are constructed to serve as experimental stimuli.

Although we have only discussed reading times here, it is also possible to look at other aspects of the eye-tracking data - in particular, regression probabilities (the supplementary material includes fixation-level data). Moreover, a sophisticated cognitive model of sentence comprehension and question answering may even be validated against the error rates for comprehension questions; that is, a question that leads to more errors by humans should also be more difficult to answer for the model.

The present data set can easily be extended by increasing the number of subjects, but more interesting future additions could include sentences from different source types (e.g., expository texts), additional data types (e.g., EEG), and material in other languages. 
Author note The research presented here was funded by the European Union Seventh Framework Programme (FP7/2007-2013) under Grant 253803 awarded to the first author, and by a grant from the Economic and Social Research Council of Great Britain (RES-620-286001) awarded to the Deafness Cognition and Language Research Centre.

\section{Appendix 1 Data files}

The online supplementary data consist of eight text files: one README file and seven data files. Two files contain stimuli data (stimuli.txt and stimuli_pos.txt), two contain subject data for the two studies (selfpacedreading.subj.txt and eyetracking.subj.txt), and three files contain reading data (selfpacedreading.RT.txt, eyetracking.RT.txt, and eyetracking.fix.txt). Each data file is formatted as a tab-delimited table with the first line consisting of the table's column names. The contents of the stimuli, subject, and reading data files are explained below in Tables 2, 3, and 4, respectively. The same information, with a few additional notes, is presented in the README file.

Table 2 Description of stimuli data files

\begin{tabular}{|c|c|c|}
\hline File name & $\begin{array}{l}\text { Column } \\
\text { name }\end{array}$ & Description \\
\hline \multirow[t]{4}{*}{ stimuli.txt } & sent_nr & Sentence number \\
\hline & sentence & The sentence, as a single string \\
\hline & question & $\begin{array}{l}\text { Comprehension question } \\
\text { (or hyphen if no question) }\end{array}$ \\
\hline & answer & $\begin{array}{l}\text { Correct answer to comprehension } \\
\text { question (or hyphen if no question) }\end{array}$ \\
\hline \multirow[t]{2}{*}{ stimuli_pos.txt } & sent_nr & Sentence number \\
\hline & pos & $\begin{array}{l}\text { Sequence of part-of-speech tags } \\
\text { (Penn Treebank style) }\end{array}$ \\
\hline
\end{tabular}

Table 3 Description of subject data files

\begin{tabular}{|c|c|c|}
\hline File name & $\begin{array}{l}\text { Column } \\
\text { name }\end{array}$ & Description \\
\hline \multirow[t]{6}{*}{ selfpacedreading.subj.txt } & subj_nr & $\begin{array}{l}\text { ID-number of subject in } \\
\text { self-paced reading study }\end{array}$ \\
\hline & age & Subject's age in years \\
\hline & age_en & $\begin{array}{l}\text { Age at which subject } \\
\text { began learning English } \\
\text { (0 for native speakers) }\end{array}$ \\
\hline & $\operatorname{sex}$ & Subject's sex (f/m) \\
\hline & hand & Subject's handedness (r/l) \\
\hline & correct & $\begin{array}{l}\text { Fraction of correct responses } \\
\text { to comprehension questions }\end{array}$ \\
\hline eyetracking.subj.txt & subj_nr & $\begin{array}{l}\text { ID-number of subject in } \\
\text { eye-tracking study }\end{array}$ \\
\hline
\end{tabular}

Table 3 (continued)

\begin{tabular}{|c|c|c|}
\hline File name & $\begin{array}{l}\text { Column } \\
\text { name }\end{array}$ & Description \\
\hline & age & Subject's age in years \\
\hline & age_en & $\begin{array}{l}\text { Age at which subject } \\
\text { began learning English } \\
\text { (0 for native speakers) }\end{array}$ \\
\hline & monoling & $\begin{array}{l}\text { Is } 1 \text { if the subject is } \\
\text { monolingual, } 0 \text { for } \\
\text { multilinguals }\end{array}$ \\
\hline & sex & Subject's sex (f/m) \\
\hline & hand & Subject's handedness (r/l) \\
\hline & correct & $\begin{array}{l}\text { Fraction of correct responses } \\
\text { to comprehension questions }\end{array}$ \\
\hline
\end{tabular}

Table 4 Description of reading data files

\begin{tabular}{|c|c|c|}
\hline File name & $\begin{array}{l}\text { Column } \\
\text { name }\end{array}$ & Description \\
\hline \multirow[t]{8}{*}{ selfpacedreading.RT.txt } & subj_nr & $\begin{array}{l}\text { ID-number of subject in } \\
\text { self-paced reading study }\end{array}$ \\
\hline & sent_nr & Sentence number \\
\hline & sent_pos & $\begin{array}{l}\text { Position of sentence in } \\
\text { presentation sequence }\end{array}$ \\
\hline & correct & $\begin{array}{l}\text { Correctness of response } \\
\text { to comprehension } \\
\text { question (c for correct, } \\
\text { e for error, hyphen if } \\
\text { there was no question) }\end{array}$ \\
\hline & answer_time & $\begin{array}{l}\text { Time in milliseconds } \\
\text { between question } \\
\text { presentation and } \\
\text { response, or } \mathrm{NaN} \\
\text { if there was no } \\
\text { question }\end{array}$ \\
\hline & word_pos & $\begin{array}{l}\text { Position of word in } \\
\text { sentence }\end{array}$ \\
\hline & word & Presented word \\
\hline & RT & $\begin{array}{l}\text { Time in milliseconds } \\
\text { between word } \\
\text { presentation and } \\
\text { key press }\end{array}$ \\
\hline \multirow[t]{6}{*}{ eyetracking.RT.txt } & subj_nr & $\begin{array}{l}\text { ID number of subject } \\
\text { in eye-tracking study }\end{array}$ \\
\hline & sent_nr & Sentence number \\
\hline & sent_pos & $\begin{array}{l}\text { Position of sentence in } \\
\text { presentation sequence }\end{array}$ \\
\hline & correct & $\begin{array}{l}\text { Correctness of response } \\
\text { to comprehension } \\
\text { question (c for correct, } \\
\text { e for error, hyphen if } \\
\text { there was no question) }\end{array}$ \\
\hline & answer_time & $\begin{array}{l}\text { Time in milliseconds } \\
\text { between question } \\
\text { presentation and } \\
\text { response, or NaN } \\
\text { if there was no } \\
\text { question }\end{array}$ \\
\hline & word_pos & $\begin{array}{l}\text { Position of current } \\
\text { word in sentence }\end{array}$ \\
\hline
\end{tabular}


Table 4 (continued)

\begin{tabular}{|c|c|c|}
\hline File name & $\begin{array}{l}\text { Column } \\
\text { name }\end{array}$ & Description \\
\hline & word & Current word \\
\hline & RTfirstfix & $\begin{array}{l}\text { First fixation time } \\
\text { on current word } \\
\text { (or } 0 \text { if word not } \\
\text { fixated) }\end{array}$ \\
\hline & RTfirstpass & $\begin{array}{l}\text { First-pass reading } \\
\text { time (or } 0 \text { if word } \\
\text { not fixated) }\end{array}$ \\
\hline & RTrightbound & $\begin{array}{l}\text { Right-bounded reading } \\
\text { time (or } 0 \text { if word } \\
\text { not fixated) }\end{array}$ \\
\hline & RTgopast & $\begin{array}{l}\text { Go-past reading time } \\
\text { (or } 0 \text { if word not } \\
\text { fixated) }\end{array}$ \\
\hline \multirow[t]{9}{*}{ eyetracking.fix.txt } & subj_nr & $\begin{array}{l}\text { ID number of subject } \\
\text { in eye-tracking study }\end{array}$ \\
\hline & sent_nr & Sentence number \\
\hline & gaze_x & $\begin{array}{l}\text { Horizontal pixel } \\
\text { coordinate of fixation } \\
\text { location }(0=1 \mathrm{eft} \\
\text { edge; } 39=1 \text { left margin; } \\
1,024=\text { right edge })\end{array}$ \\
\hline & gaze_y & $\begin{array}{l}\text { Vertical pixel coordinate } \\
\text { of fixation location } \\
(0=\text { top of display; } \\
768=\text { bottom of } \\
\text { display })\end{array}$ \\
\hline & fix_duration & $\begin{array}{l}\text { Duration of fixation } \\
\text { in milliseconds }\end{array}$ \\
\hline & letter_pos & $\begin{array}{l}\text { Fixated letter position } \\
\text { in sentence (including } \\
\text { spaces). Position } 0 \\
\text { is directly to the left } \\
\text { of the first letter }\end{array}$ \\
\hline & word_pos & $\begin{array}{l}\text { Position of fixated word } \\
\text { in sentence, or NaN } \\
\text { if no word fixated }\end{array}$ \\
\hline & word & $\begin{array}{l}\text { Fixated word, or hyphen } \\
\text { if no word fixated }\end{array}$ \\
\hline & blink & $\begin{array}{l}\text { Location of detected } \\
\text { blink relative to current } \\
\text { fixation (before/after/ } \\
\text { both, or hyphen if no } \\
\text { blink detected) }\end{array}$ \\
\hline
\end{tabular}

\section{Appendix 2 Sentence stimuli}

Table 5 shows all 205 sentences used in the eye-tracking study. The same sentence stimuli (and 156 others) were presented in the self-paced reading task.

Table 5 Sentence stimuli in eye-tracking study

Anne lost control and laughed.

Billy wrote on the envelope.

He called over his shoulder.

He stayed against the wall.
Helen ran to the toilet.

I cannot tell you more.

Michael gave Adam two pounds.

Roger smiled and sat down.

Things were looking up again.

This man's hair is black.

Turn your hearing aid up.

You'll demand nothing of me.

A horse has thrown a shoe.

A tube train took his legs.

Five will be listening for sure.

Gordon felt his anger build up.

Harry smiled at his little brother.

He needed putting in his place.

He shouted and the calling ceased.

He uses his belt on you.

He's broken his wrists very badly.

I am touched deeply in places.

I don't want to hear it.

I knew I heard your voice.

I wouldn't want to miss this.

Jack walked up to the door.

Ross sat back down and shivered.

She couldn't help feel for Alex.

The bored looking soldier just pointed.

The campaign will pay for itself.

They're riding out to meet them.

We barely escaped with our lives.

We've been travelling almost three days.

Alice is looking for somewhere to live.

Alan forgot to shave again this morning.

Have a carriage sent for us immediately.

He probably doesn't want people to know.

He put the fork on the table.

I'll give him more than a slap.

Andrew nodded and stood against the counter.

Looks like a walk did the trick.

Sam felt proud when he went home.

Scott got up and washed his plate.

Simon nodded and walked into the room.

Steve sat down to eat his lunch.

Ted smiled and bit his bottom lip.

Thomas stepped back and shook his head.

Tom stood up and wiped his jeans.

Tony stopped off at his first delivery.

Normally they want to cut things up.

Powerful in the wrong hands, is that.

She had refused to leave her home.

She hid the boxes and matches well.

The bored looking soldier continued looking bored.

The dead must not kill the living.

The prison guard walked along the row. 
Table 5 (continued)

The van is your lead, follow that.

You're getting up early in the morning.

After lunch he was told he had visitors.

Albert spoke before Barbara had a chance to.

Come within the walls to escape the enemy.

Follow me closely and watch for their leader.

He called out but she did not move.

He sat down and began to eat breakfast.

He slammed the knife down on the lamb.

He staggered into the chair at his desk.

I do not spare the birds a killing.

I think our friend's demands are well justified.

Let us leave these poor people in peace.

Walter closed the door and took a breath.

William sat down and tucked into his breakfast.

Alec stood against the wall to steady himself.

No-one else had dared step within the ring.

None of the city people dress like that.

She saw the throwing knife in his hand.

She was smiling in the dark, teeth flashing.

Shut your smart foul mouth and sit down.

Tell me what really happened to the truck.

The door was opened and Alexander walked out.

There were choked screams and shouts of dismay.

There will be men to kill either way.

They were definitely holding hands underneath the table.

Claudia still teaches and still claims to hate it.

Burn him now, don't wait for him to escape.

Don't die of cold before you die in battle.

Good God, if you are watching, give me strength.

He heaved his shoulders and swung the axe again.

$\mathrm{He}$ is after glory and heads for his hall.

He just wished he could talk to his dad.

He lay his sword aside and extended his hands.

He sighed and walked back to the wood shop.

He smiled when she let out a big yawn.

He was leaning against his truck smoking a joint.

I was thinking of getting the band together again.

It is a narrow ship, much like our own.

Arthur placed the bars of chocolate on the counter.

John gave Bernard a hard slap on the head.

Let's get out and I'll buy you a drink.

Let's have the gates closed and go home early.

Andrew closed the office door on the way out.

Charles felt sick to the pit of his stomach.

Christopher groaned and lay his hands across his stomach.

Dave kicked him in the stomach and Paul groaned.

Dexter opened his letter and found a photograph inside.

Duncan took a breath and wanted to be sick.

Edward washed his hands and flicked water at Bob.
Table 5 (continued)

She turned and saw him standing in her path.

They turned round just as Frankie walked toward them.

Underneath the table her hand was gripping the chair.

Whether Peter heard him or not Gabriel didn't care.

You give me a lead and I'll follow it.

All the bowls from the empty tables are cleared up.

His dark hair was just visible under his white hat.

His men will not follow him and they are few.

I'll break your neck if you don't fix that water.

Ian gave Geoffrey a hard slap across his right ear.

Jake smiled again at his baby daughter, she was perfect.

Jimmy liked the fact they were calling him Jim.

Brian sniffed and wiped his grubby hand across his nose.

Phil let him go and Charlie fell to the ground.

Let me through and you'll hear nothing more of it.

Men could be paid to do all sorts of things.

Gilbert sat as still as he could nursing his lip.

Jacques sighed and tried to move out of the way.

Jamie took a cigarette and Andy gave him a light.

Joseph walked into the office and removed his flat cap.

She would soon be found if she tried to hide.

The brothers stood up and came down from the platform.

Anthony was approached, just as he had predicted, in the park.

Despite what Frank had told her Ellen thanked the young soldier.

He called earlier and I already arranged to go swimming tomorrow.

He drove his truck home and walked down to the village.

He held his mother tight and she cried into his chest.

He went to the door and walked out of the room.

His helmet was lost but he could still do some damage.

Ken just hoped he wasn't taking his temper out on Chris.

Lawrence rubbed the back of his neck and hung his head.

Lewis sat down and Lucy laid her hand on his cheek.

Matthew stood against the wall with his hands behind his back.

Run along home now and bring us some men to kill.

She just kept telling herself he had to learn a lesson.

She wound up talking to Barry about her time in India.

The gate was double, one huge mass of wood following another.

The gathered villagers took a step back, almost as one man.

We shall arrive properly or you will never live this down.

While they sat drinking their tea, Mick dug them a trench.

You know better than to talk to your mother like that.

You know that I will do whatever you ask of me.

You shouldn't have been racing my truck in the first place.

A smile came to his lips as he thought of an idea.

All last week there was a white van parked across the street.

Finally Maria sat down with a cup of tea and a sandwich.

He didn't seem to mind that she was screaming in his ear.

He drank too much at times and washed too little at times.

He folded his arms across his chest and put out his lip.

He had another shock when they told him he was moving cells. 
Table 5 (continued)

He put his hands in his pockets and leaned against the truck.

He was built with muscle and liked to throw his weight around.

I am trying, old man, but I would rather kill the ship.

I shall have a victory and I want it to be remembered.

In the morning Mickey stood straight with his hand behind his back. In the morning at breakfast Mike smiled at the letter he received. It had been two weeks since Philip had been sent to prison. It is not the most fragrant of places but we make do. James walked in to wake Samuel at four thirty in the morning. Let us give battle to these foreign snakes once and for all. Tommy came out of the staff room toilet looking a little pale. Michael knew they never hit him and that was half the problem. Alan told Jason he would just sit outside to have his lunch. Now the man is coming who will give it back to me. She threatened to leave before and this time she just had enough. The first knife caught in her skirt and she shook it free. The last thing Alex felt like doing after work was more work. The truck was an older version of the ones the others drove. They stared at the black wall and now this offered no comfort. We should talk about the things people talk about on first dates. Why don't you tell me what happened on Saturday, step by step. Emma put her mug of tea down on the table with a bang. Bruce is looking for someone to take the spare room in his flat. From the moment we leave this spot be very careful what you say. He knocked on the door so hard that he almost broke it down. He let Donald go and he fell to the floor with a thud. He smiled again and felt like a man and not just the kid. He's got the ability to work but he just gets bored too easy. I can't see any amount of talk getting you out of this mess. I flung out my hands and they said I had broken my wrists. I mostly just pick a dry white and drink it to get drunk. Andy felt good when he got ready to go out on Saturday night. Billy knocked on the door and waited till he was told to enter. Bob sat at the entrance to the warehouse and made up a cigarette. Brian sat down at an empty table and began to eat his breakfast. One by one she placed her teeth about their necks and killed them. The shout caught him off guard and he fell back a little way. He rose from his seat and stopped mid way when Joe glared at him. He sat his son up on the table and laid his belt beside him.

If I have time at the end I'll fill you in on what happened. Henry washed his hands and sat on the seat in front of the stove. The police officer got out of the van and picked up the two cans. The speaker turned to her with a smile and a bow of his head. They say he can breathe fire and kill a man with a single word. He came back to his senses when he heard his dad stand up to him. He was already up and dressed and invited us in for a cup of tea. I know Richard drinks a little too much and has a bit of a temper. If this were a movie instead of a book this would be a good bit. James was only in the cell for an hour but it felt like a week.

\section{References}

Andrews, M., Vigliocco, G., \& Vinson, D. (2009). Integrating experiential and distributional data to learn semantic representations. Psychological Review, 116, 463-498.

Boston, M. F., Hale, J., Patil, U., Kliegl, R., \& Vasishth, S. (2008). Parsing costs as predictors of reading difficulty: An evaluation using the Potsdam Sentence Corpus. Journal of Eye Movement Research, 2, 1-12.

Boston, M. F., Hale, J. T., Vasishth, S., \& Kliegl, R. (2011). Parallel processing and sentence comprehension difficulty. Language \& Cognitive Processes, 26, 301-349.

Demberg, V., \& Keller, F. (2008). Data from eye-tracking corpora as evidence for theories of syntactic processing complexity. Cognition, 109, 193-210.

Fernandez Monsalve, I., Frank, S. L., \& Vigliocco, G. (2012). Lexical surprisal as a general predictor of reading time. In Proceedings of the 13th Conference of the European Chapter of the Association for Computational Linguistics (pp. 398408). Avignon, France: Association for Computational Linguistics.

Fossum, V. \& Levy, R. (2012). Sequential vs. hierarchical syntactic models of human incremental sentence processing. In Proceedings of the 3rd Workshop on Cognitive Modeling and Computational Linguistics (CMCL 2012) (pp. 61-69). Montréal, Canada: Association for Computational Linguistics.

Frank, S. L., \& Bod, R. (2011). Insensitivity of the human sentenceprocessing system to hierarchical structure. Psychological Science, 22, 829-834.

Frank, S. L. in press. Uncertainty reduction as a measure of cognitive processing load in sentence comprehension. Topics in Cognitive Science.

Frank, S. L., \& Thompson, R. L. (2012). Early effects of word surprisal on pupil size during reading. In N. Miyake, D. Peebles, \& R. P. Cooper (Eds.), Proceedings of the 34th Annual Conference of the Cognitive Science Society (pp. 1554-1559). Austin: Cognitive Science Society.

Just, M. A., Carpenter, P. A., \& Woolley, J. D. (1982). Paradigms and processes in reading comprehension. Journal of Experimental Psychology. General, 111, 228-238.

Kennedy, A., \& Pynte, J. (2005). Parafoveal-on-foveal effects in normal reading. Vision Research, 45, 153-168.

Kliegl, R., Nuthmann, A., \& Engbert, R. (2006). Tracking the mind during reading: The influence of past, present, and future words on fixation durations. Journal of Experimental Psychology. General, $135,12-35$.

Lilliefors, H. W. (1967). On the Kolmogorov-Smirnov test for normality with mean and variance unknown. Journal of the American Statistical Association, 62, 399-402.

Mitchell, J., Lapata, M., Demberg, V., \& Keller, F. (2010). Syntactic and semantic factors in processing difficulty: An integrated measure. In Proceedings of the 48th Annual Meeting of the Association for Computational Linguistics (pp. 196-206). Uppsala, Sweden: Association for Computational Linguistics.

Roark, B., Bachrach, A., Cardenas, C., \& Pallier, C. (2009). Deriving lexical and syntactic expectation-based measures for psycholinguistic modeling via incremental top-down parsing. In Proceedings of the 2009 Conference on Empirical Methods in Natural Language Processing (pp. 324-333). Association for Computational Linguistics.

Santorini, B. (1991). Part-of-speech tagging guidelines for the Penn Treebank project. Philadelphia, PA: University of Pennsylvania.

Schotter, E. R., Angele, B., \& Rayner, K. (2012). Parafoveal processing in reading. Attention, Perception, \& Psychophysics, 74, 5-35. 
Tsuruoka, Y. \& Tsujii, J. (2005). Bidirectional inference with the easiest-first strategy for tagging sequence data. In Proceedings of the conference on human language technology and empirical methods in natural language processing (pp. 467-474). Morristown, $\mathrm{NJ}$ : Association for Computational Linguistics.

Witzel, N., Witzel, J., \& Forster, K. (2012). Comparisons on online reading paradigms: Eye tracking, moving-window, and maze. Journal of Psycholinguistic Research, 41, 105128.

Wu, S., Bachrach, A., Cardenas, C., \& Schuler, W. (2010). Complexity metrics in an incremental right-corner parser. In Proceedings of the 48th Annual Meeting of the Association for Computational Linguistics (pp. 1189-1198). Uppsala, Sweden: Association for Computational Linguistics. 